\title{
Provision of Internet Service in any Institution is Sequel to Proper Structure Cabling- A Technical Report
}

\author{
Chizea D. Francis, Akachukwu Chichebe, Ovie EseOghene
}

\begin{abstract}
The structural cabling system is the foundation of the modern information network upon which overall information system strategies are built. Structured Cabling system presents the rules and Subsystems of structural cabling for a local-area network (LAN). A structured cabling system can alleviate the workflow disruption and network downtime associated with office restricting such as support for multiple voices, data, video and multimedia systems regardless of their manufacturer. It can be said that the structured cabling system prepares you for tomorrow, which outlives other networking components. This paper presents a technical report from one of the Largest LAN installation for nearly every building on campus, including all administrative, academic and residential buildings, and most athletic facilities. In order to carried-out this installation, extensive information was collected across 20 buildings of the entire network of FUT, Minna, Nigeria with more emphasis on SAAT network.
\end{abstract}

Index Terms - LAN, multimedia system, network downtime, structured cable

\section{INTRODUCTION}

The internet has irrevocably invaded many aspects of our daily life. What was once an obscure scientific research tool has blossomed into a communications platform used by hundreds of millions of people. Telecom providers use the internet to carry critical voice communications. Airline tickets, hotel reservations and car rentals can be booked with a click of a mouse. Whole industries have sprung into existence with business models that depend entirely on Internet infrastructure to reach their customers. It is also an established fact the internet in any institutional environment enhances the development of teaching, learning research works, administration and community services which support innovation and invention. As technology continues to evolve, the corporate network must support voice, data, video and multimedia applications which are well accommodated and faster when there is a structured cabling system [1]. The growing size of networks and the introduction of higher-speed access methods create an overwhelming need for reliable and manageable cabling systems in Federal University of Technology (FUT), Minna, Nigeria which has been using wireless radios to transmit signals within the campus.

However careful planning was implemented to prevent congestion that can dramatically diminish the network performance. The performance requirement of different media types installed at each work station varies depending on distance and weather. The internet itself does not only transmit a large amount of data through fibre optic cabling but also employs a bulky amount of T1/T3 lines that run over standard copper wirings. This means that electronic signals are being transmitted over a metallic conductor which is the most reliable way to transmit or receive data/voice on the planet [2]. Although wire cables are susceptible to interference and various solutions such as shielded cables can be used however there are several types of cables which are commonly used with LANs. In some cases, a network will utilize only one type of cable type, other networks will use a variety of cable types. The type of cable chosen for a network is related to its topology, protocol and network size. Understanding the characteristics of different types of cables and how they relate to other aspects of the network is necessary for the development of a successful network.

\section{TYPES OF CABLES}

Cabling systems that can be used to connect all servers, computers and other network devices together can be grouped into four types namely:

- Unshielded Twisted Pair (UTP) Cable

- Shielded Twisted Pair (STP) Cable

- Coaxial Cable

- Fiber Optic Cable

\section{A. Unshielded Twisted Pair (UTP) Cable}

UTP is the most popular and generally the best option for campus networks. The quality of UTP may vary from telephone-grade wire to extremely high-speed cable. The cable has four pairs of wires inside the jacket. Each pair is twisted with a different number of twists per inch to help eliminate interference from adjacent pairs and other electronic devices. The standard connector for unshielded twisted pair cabling is an RJ-45 connector. RJ stands for Registered Jack, implying that the connector follows a standard borrowed from the telephone industry.

\section{B. Shielded Twisted Pair (STP)}

Shielded twisted pair may be the solution to environments with lots of potential interference, or in extremely sensitive environments that may be susceptible to the electrical current. Shielded cables also help to extend the maximum distance of the cables.

Shielded twisted pair cable is available in three different configurations:

- Each pair of wires is individually shielded with

- There is a foil or braid shield inside the jacket covering all wires (as a group)

- There is a shield around each individual pair, as well as around the entire group of wires (referred to as double shield twisted pair) 


\section{Coaxial Cable}

Coaxial cabling has a single copper semiconductor at its centre. A plastic layer provides insulation between the centre conductor and braided metal shield. The metal shield helps to block any outside interference from fluorescent lights, motors and other computers. There are two types of coaxial cabling: they are thick coaxial and thin coaxial. Thin coaxial cable also referred to as thinnet i.e. 10 Base 2 refers to specifications for thin coaxial cable carrying Ethernet signals while the thick coaxial cable is also referred to as thicknet i.e. 10base 5 refers to the specifications for thick coaxial cable carrying Ethernet signals.

\section{Fiber Optic Cable}

Fiber optic cabling consists of a center glass core surrounded by several layers of protective material. It transmits light rather than electronic signals eliminating the problem of electrical interference. This makes it ideal for certain environments that contain a large amount of electrical interference. It has made it the standard for connecting networks between buildings, due to its immunity to the effects of moisture and lighting. Fiber optic cable has the ability to transmit signals over much longer distances than coaxial and twisted pair.

There are two common types of fiber cables - single mode and multimode. Single mode can provide more distance, but it is more expensive while Multimode cable has a larger diameter. However, both cables provide high bandwidth at high speed [3].

\section{SELECTING A STRUCTURED CABLING}

There are several factors that must be taken into consideration when determining the category or class of cabling that will be used in a network infrastructure and local area network (LAN) [4], [5]. This is true for both copper and fiber.

Factors that must be taken into consideration are:

- An expected installed lifetime of the cabling plant.

- Applications that will run on the cabling plant over its useful life.

- The time frame during which standards, applications and electronics manufacturers will support the cabling plant

- Cost of active electronics

- Warranty length and covered components

Cabling systems, both copper and fiber, are designed to perform for 10 years, supporting 2-3 generations of active electronics. Overall lifecycle costs should be closely considered. Cabling standards are regularly written and reviewed, For instance, ANSI/TIA/EIA (Now TIA, Telecommunication industry Association) standards are reviewed every 5 years. ISO/IEC standards are written with a target lifespan of 10 years. IEEE application performance standards are written, revised or amended based on current manufacturing and product capabilities, application needs and contribution from companies, including cabling manufacturers that participate in the standard process.

Active electronic manufacturers design equipment based on three factors: capabilities of the underlying Infrastructure, industry standards and market share of the installed infrastructure. The technology must be technically feasible, have broad market appeal, and provide a unique feature set while coexisting with other technology. It would be virtually impossible to sell any active equipment that automatically requires replacement of a cabling plant.

System life cycles are based on current standards, developments, pending revisions, and the categories ability to support upcoming applications, for example, non- augmented category 6 (6A) systems capable of supporting 10GBASE-T up to 100 meters. Category 7/Class F systems enjoy the longest lifecycle and are expected to support future applications beyond 10GBASE-T such as $40 \mathrm{~Gb} / \mathrm{s}$.

\section{A. Advantages of Structured Cabling Systems (SCS)}

Structured cabling standards specify generic installation and design topologies that are characterized by a "category" or "class" of transmission performance. These cabling standards, are subsequently referenced in applications standards, developed by the committee such as IEEE and ATM as a minimum level of performance necessary to be realized by specifying standards- compliant structured cabling which are:

1. Consistency: An SCS means the same cables exist everywhere in the building. You'll know what to expect instead of encountering layers of old cabling with unknown destinations.

2. Support for multi-vendor equipment: A standards-based cable plant will support your applications and hardware even after you change or mix and match vendors. Upgrading will be highly simplified.

3. Simplify moves/adds/changes: People and equipment are constantly moving locations. With structured cabling, the network resources are always there and ready to go. There's no waiting for someone to make a drop in a new room.

4. Simplify troubleshooting: Even cables that were installed correctly can fail - and they do. With a structured wiring system, problems are easier to isolate, easier to fix and less likely to break down the entire network.

5. Support for future applications: if you install a Cat 5, or even Cat 6 complaint system, your cable plant will support future applications with little change if any system upgrades [1].

\section{FUT MINNA SITE DESCRIPTION}

Facts about the establishment and location of the Federal University of Technology (FUT), Minna can be obtained in [6]. The University has many attractive buildings that are networked together. Among these is the Senate building which is the administrative building of the university. School of Engineering and Engineering Technology (SEET), School of Information and Communication Technology (SICT), School of Entrepreneurship and Management Technology (SEMT), Information Technology Services (ITS) building which manages the internet services on campus, School of Agriculture and Agricultural Technology (SAAT) and the School Library. Others are Units such as Works Department, Directorate of collaboration and linkages (DCAL), Centre of Distant Education and Learning (CODEL) are few to be mention. 


\section{A. Information Technology Services (ITS) Centre}

ITS (formerly called Computer Center) is a department created by the end of 1998. In 2003 VSAT facility was acquired to provide internet facility to the institution. With an increase in internet usage, VSAT cannot longer provide the desirable internet access despite the amount of money spent on bandwidth due to slowness in data propagation and high bit error rate. ITS have undergone so many reformations to this present stage. As a result of this, the university is now connected to the internet via fiber through microwaves antenna.

ITS unit has a total number of twenty- eight staff working in various departments such as Networking section, MIS section, Hardware and maintenance section and Security and Monitoring section. ITS is saddled with the management of internet services and other IT responsibilities such as repair and maintenance of systems, installation of radios, VSAT installation, Database Management and so on. ITS building can be described as the eye of the institution that projects the image of the institution to the outside world. It is the center of the network where all wires originate and where most of the equipment is located. It is also the main concentration point of the network on campus that controls the rest of the telecommunication rooms on campus. There are several telecommunication rooms located on each erected building on campus since the network is spread across the whole campus. The telecommunication rooms contain switches, radios (transmitting or receiving a signal from a demarcation point), batteries and inverter powering the switches and the radios. The abducted topology here is Star-Bus which is planned so that there is network backbone from ITS building to SET. SET remains the intermediate cross-connect to SICT, SEET and SEMT, while other buildings are connected with a point to point radio link which is terminated on a switch which in turn feed all the work areas and wireless radio terminated on the switch. Among the buildings connected with radio link backup are Senate buildings, (SAAT), male, female hostel and library. Fig 1. Illustrates internet connection on Main Campus.

However, an effort is on course to extend the fiber backbone to other buildings where radio link are initially used as a backbone.

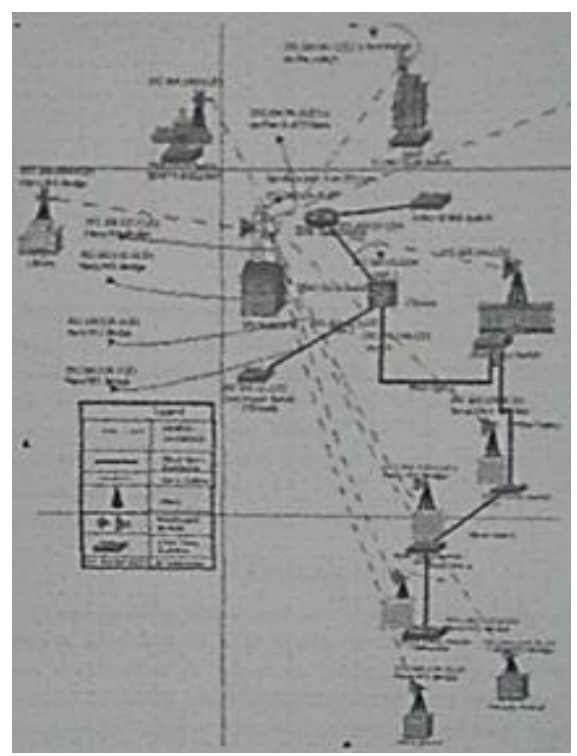

Fig. 1 Network Diagram of FUT Minna Campus

\section{B. Installation and implementation of LAN CABLE in SAAT}

The site is surveyed and the materials needed are listed and bought before the installation and implementation of structured cabling of SAAT. The materials used for the installation of LAN in this building are given in appendix table II with the building plan diagram. In this building, there are three floors including the ground floor. The floors have the following number of work areas listed below:

1. The Floor 2: has an open plan and there are 45 work areas

2. Floor 1: has an open plan and there are 20 work areas

3. The Ground: consists of laboratories and offices which have a total work area of 25 . The two switch rooms are on the second floor and it controls the whole building via a $2960 *$ port Cisco Switch that connects the whole 2960 48port Cisco Switch together.

The installation process of this cable operation project begins with the rough work (rough-in-phase) in the Telecommunication Room (TR) since one end of every cable will be terminated in the TR. The equipment on the distribution rack is properly set up to save time during the cabling process. Different types of cable run will require different steps. During this phase, this cable is pulled from a work area, a staging area, individual rooms or work area. Each cable is labelled on both ends for identification. In the work area, the extra cable is pulled so that there is plenty to work with when terminating. If a cable will behind a wall is pulled out at the termination end so that it is ready for termination in the next phase. Before cables are installed, the surface mounted trunk pipe (raceways) is secured to the wall along a cable path in various rooms that is to be networked following the manufacturer's recommendations. During the pulling of cables from one work area to another, holes are drilled through the walls that the cable will pass through.

The Penetration is usually sleeved by inserting a small section of conduit in the hole. The trucking pipe must be large enough to hold the cables, with room for additional cables in the future. Cables are then pulled through the trunk pipe. After the cables have been pulled through the trunk pipe, the trunk pipe must be sealed with its cover. Then the cables that have been pulled through to the outlets will have to be pulled into the telecommunications room to finish palling he cable at that end. The end of the horizontal cable in the work area is usually terminated with colour coded jacks i.e. RJ 45 jacks unless a consolidation point or (Multi-user Telecommunication outlet Assembly) MUTOA will be used. In this case, the horizontal cable will be terminated directly to the consolidation point or by an RJ45 plug when using a MUTOA. The jack is terminated with approximately 15 to $20 \mathrm{~cm}$ ( 6 to 8 inches) of the cable coming out of the wall, this excess cable is carefully coiled into the wall or wall box when the jack is installed. This excess cable can also be used re-terminate the jack at a later date. It can also be used to remove the faceplate and add another jack to the outlet. The other end of the cable will be typically be terminated in the telecommunications room by an RJ- 45 jack when using modular patch panels, or directly to standard patch panels mounted on the distribution rack as shown in Fig 2. Wires are inserted into the appropriate locations on termination blocks. Then the punch down tool is placed over the wires, depending on the type of termination hardware used. The wire is forced between two insulation displacement connection and excess 
wire is cut off in the same operation. The connection is referred to as insulation displacement because the insulation is pushed out of the way the contacting points on the terminal. At workstation terminals, wires in the jack will commonly lose contact with the pins. This occurs because the patch cord to the work area is often pulled, kicked or stretched by the workstation users. Cables are also punched down on termination blocks mounted on the wall for the faceplates and at the rear of patch panels. The distribution rack mounted on the wall must have a minimum of 1 meter ( 3 feet) of the workspace clearance in the front and rear of the rack. A 55.9$\mathrm{cm}$ (22inch) floor plate is used to mount the distribution rack. The floor plate provides stability and determines the minimum distance from the final position of the distribution rack.

After the cables have been terminated, the cable should be plugged into a cable tester to verify that the termination was done correctly. A uniform wiring scheme must be used throughout a patch panel system. For example, if the T568A wiring plan is used to terminate information outlets or jacks, the T568A scheme should be used to terminate patch panels as well. The same is true for the T568B wiring scheme. In this paper T568A straight through cable scheme is used throughout. The straight through cable is the most common patch cable. It has the same wiring scheme on both ends of the cable. Therefore, a pin in one end is connected to the corresponding pin number on the other end. These types of cables are used to connect PCs to a network, a hub, or a switch.

When the cable is terminated correctly and tested, the labelling is then carried out because labelling is another important part of a structured cabling system. Cables should be clearly labelled on both ends to avoid confusion. TIA/EIA-606-A specifies that each hardware termination unit should have a unique identifier marked on the unit or on its label. When identifiers are used at the work are, station terminations must have a label on the faceplate, the housing, or the connector. Most requests for proposals and specifications require computer-generated labels. These labels are permanent, legible and more professional looking [5].

\section{RESULTS AND DISCUSSION}

The equipment used in testing is LAN Tester. The result of the testing is as shown below;

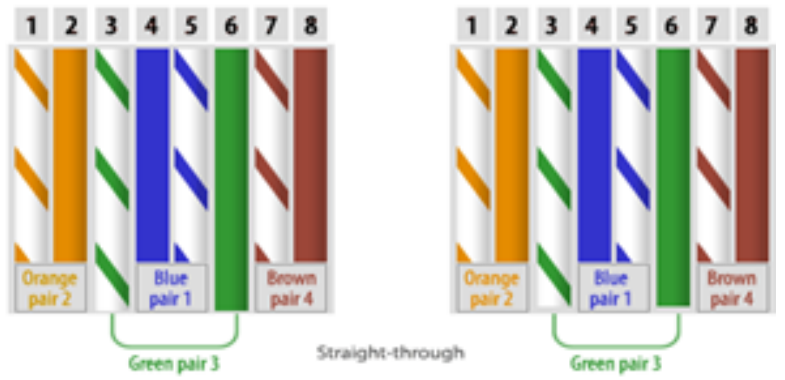

Figure 2. Straight Cable Termination

The LAN cable has four twisted pairs namely: Orange-white, Orange; Green-white, Green; Blue-white, Blue, Brown-white and Brown as in Figure 2. These strands are arranged on both ends just as listed above using the Straight through cable format. If after termination, one of the cable strands fails to come up. It will be indicated on the LAN Tester and the Engineer will be able to re-crimp the particular cable again. Otherwise, the cable is ready for Data/Voice transmission. Table 1 illustrates the results of LAN cabling for Floor 2, Floor 1 and Ground floor.

Table 1: The Result of LAN Cabling of all the Floor

\begin{tabular}{|l|l|l|l|}
\hline $\begin{array}{l}\text { Work Area } \\
\text { Label Number }\end{array}$ & $\begin{array}{l}\text { From } \\
\text { Areas }\end{array}$ & $\begin{array}{l}\text { To } \\
\text { TR }\end{array}$ & REMARKS \\
\hline 101 & 101 & 209 & OKAY \\
\hline 102 & 102 & 209 & OKAY \\
\hline 103 & 103 & 209 & OKAY \\
\hline $104 \ldots \ldots 125$ & $104 \ldots \ldots \ldots 125$ & 209 & OKAY \\
\hline 201 & 201 & 209 & OKAY \\
\hline 202 & 202 & 209 & OKAY \\
\hline $203 \ldots \ldots .220$ & $203 \ldots \ldots .220$ & 209 & OKAY \\
\hline 301 & 301 & 209 & OKAY \\
\hline 302 & 302 & 209 & OKAY \\
\hline $303 \ldots \ldots \ldots 320$ & $303 \ldots \ldots \ldots 320$ & 209 & OKAY \\
\hline A1 & A1 & 209 & OKAY \\
\hline A2 & A2 & 209 & OKAY \\
\hline A3 & A3 & 209 & OKAY \\
\hline A4 & A4 & 209 & OKAY \\
\hline
\end{tabular}

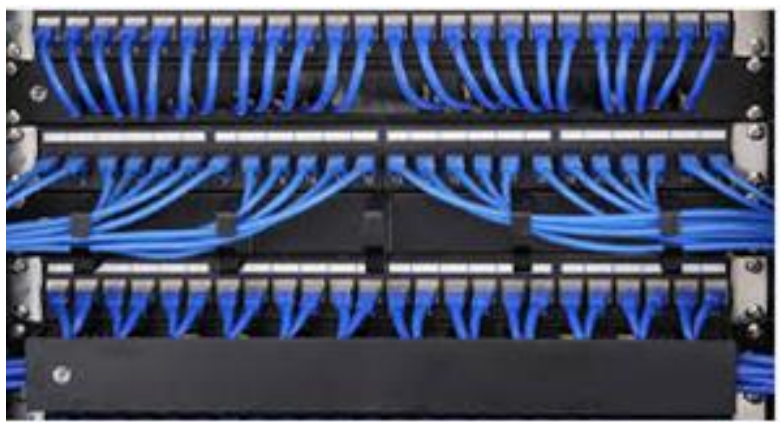

Fig. 2. Termination of Cables on the Patch Panel

\section{CONCLUSION}

The aim of the project was achieved. Structural LAN cabling system was installed in SAAT which aid academic and research activities in this school. It is a known fact in FUT Minna that, the provision of Internet and the installation of LAN in SAAT have made serious impact on both staff and students in that school. SAAT has more Professors and Senior Lecturers than any other department in FUT Minna. LAN is critical for performance as well as reliability for easy Internet surfing and has also solve the problem of wireless transmission over a long distance which causes fading. Achieving a good design and installation of cables is based on the category or class of cabling that was used as a network infrastructure and local area network (LAN). This is true for both copper and fibre. Factors that were taken into consideration during installation were:

1. Expected installed life time of the cabling plant

2. Applications that will run on the cabling plant over its useful life

3. Time frame during which standards, applications and electronics manufacturers will support the cabling plant and

4. Cost of active electronics 
These factors formed the decision making during the staging of planning, designing and implementation.

\section{RECOMMENDATION}

When walking in walls Ceilings, or attics, it is extremely important to remember to turn off the power to all circuits that go to, or pass through, the work area. If it is unclear whether there are wires that pass through the section of the building, a good rule to follow is to shut off all power. Prober installation of equipment racks and patch panels in the TR should be carried out to allow for easy modifications to the cabling installation in the future as regards to when placing equipment into equipment racks, cable routing and cable management. Also a uniform wiring scheme must be used throughout a patch panel system. For example, if the T568A wiring plan is used to terminate information outlets or jacks, the T568A scheme should be used to terminate patch panels as well. The same is true for the T568B wiring scheme too [5].

\section{REFERENCES}

[1] Structured Cabling - Network Cabling to handle your companies ene-to -end satellite Communications. www.antennapro.net/Structured Cabling.htm - Cached. 2011.

[2] Wired vs. Wireless. -Skullbox.net, by Erik Rodriguez Audience: Newbies-self Learners Last Updated: 3/16/2011 12:10:22 AM Original Creation Date 3/12/2005 12:10:22 AMK

[3] Chapter4: Cabling University of South Florida http://fcit.usf.edu/network/chap4/cha4.htm. Florida center for Instructional Technology, college of Education, Tampa, Florida 33620,2011, Dr RoyWinkelman, Director.

[4] ebook - network- cabling-basics- and 10G.pdf, Network Cabling Basics, ISO9001 Certified, ISO14001 Certified, www.simeon.com. “TB_AlienCrosstalk Rev.A 10/07,"c 2007 Siemon. Author- Priscila

[5]Structured Cabling Supplement, Cisco Networking Academy Progrm .CCNA 1: Networking basics v3.1, Copy c 2004, Cisco System Inc.

[6] Federal University of Technology Minna. www.futminna.edu.ng, c2008, by ITS department.

[7] 600 Watt Pure Sine Wave Inverter, Donrowe.com.Available: http://www.dronrowe.com/inverters/puresine_600html. Retrieved Dec 14,2010 .

[8] ABS Alaskan. (2006). DC to AC Power Inverters. Available: http://www.absak.com/basic/inverters.html. Retrieved December 4, 2010 ,

[9] Bellis, Mary. William Stanley Jr. Available: http://inventors.about.com/library/inventors/blstanley.htm. Retrieved March16,2011.

[10] Go Power 600Watt Modified Wave Inverter. 4 Lots.com. Available: http://www.4lots.com/browseproducts/GoPower600WattInverter.html . Retrieved April 14,2006

[11] Sizing and inverter Batter bank. Available: www.majorpower.com/invcerters/battery_sizing faq.pdf. Retrieved July 12, 2011. 